\title{
Teacher's Roles to Facilitate Active Learning
}

Alexandra Kudryashova ${ }^{1}$

Tatyana Gorbatova²

Svetlana Rybushkina ${ }^{3}$

Elena Ivanova ${ }^{4}$

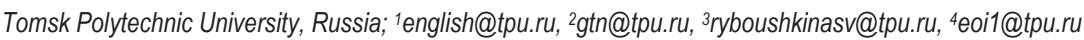

\author{
Doi:10.5901/mjss.2016.v7n1p460
}

\section{Abstract}

This article gives a detailed analysis on the role of a teacher in the modern educational environment and justifies the need to reconsider instructional strategies following the shift from teaching to learning that has recently appeared in higher professional education and was provoked by a growing access to professional knowledge and revision of requirements to university graduates under the pressure of societal, academic and industrial community. The Bloom's taxonomy and the 5E's Instructional model that are commonly applied in active learning are reviewed and compared. Their significant similarity and compatibility is used to define the teaching approaches that best fit the new educational goals. A teaching model is proposed to provide educators with guidelines on how to facilitate a successful active learning where the authors specify optimal teaching roles for each learning phase.

Keywords: teacher's role, teaching model, active learning

\section{Introduction}

Since the Internet opened access to unlimited resources on any possible topic, teachers have lost their value as the major source of knowledge and students' expectations from educators in a classroom have changed dramatically (Hargreaves 2003). Revision of the teacher's role was also provoked by modernization of requirements to university graduates under the pressure of societal, academic and industrial community (Selevich, Selevich and Golubeva 2015). In the modern world specialists should be able to not only make use of obtained knowledge but also demonstrate leadership, make decisions in non-standard situations and find, analyze and process information on their own responsibility (Chodasováa and Tekulová 2015).

J. Patrick McCarthy and Liam Anderson describe traditional teaching as lecturing being "the centerpiece of instruction, where students passively absorb pre-processed information and then regurgitate it in response to periodic multiple-choice exams" (McCarthy and Anderson 2000, p. 279). The major role of a teacher then is to transmit and assess knowledge. This teaching strategy provides incentives to learn only at the surface (passive) level rather than at the deep (active) level (Marton and Saljo 1976; Jaques 1992) and does not fit the modern educational environment and goals.

With the change in the vision of modern specialists and an increasingly open access to knowledge, education is now referred to as "experiences in which students are thinking about the subject matter" as they interact with the instructor and each other (McKeachie 1999; Chickering and Gamson 1987). Therefore the traditional teachers' function of transmitters of information has transformed into that of organizers and partners in students' learning (Clapper 2009). Nowadays, teachers and students play an equally active role in the learning process (Gelisli 2009; Ercan 2004) and active learning strategies refer to a variety of collaborative classroom activities ranging from long-term simulations to fiveminute cooperative problem solving exercises (Bonwell and Eison 1991; Sutherland and Bonwell 1996). Teaching and assessment become connected and students' level of gained knowledge is measured through both formal and informal assessments including written and oral questions, performance ratings, project reviews, portfolios and self-reporting (Stiggins and Chappuis 2011).

According to Deborah Nolan (2010) the main aim in learning in contrast to teaching is to shift the focus from the teacher and the delivery of course content to the students and their active engagement with the course material. Through 
active learning techniques students can escape the traditional role of passive receptors and learn and practice how to apprehend knowledge and skills and use them meaningfully. Accepting the need to abandon traditional teaching, the question is, however, how teachers can facilitate student's learning and what their roles are.

This papers aims to describe teacher's behavior that can facilitate active learning. Although generally accepting the new educational paradigm, teachers often do not recognize the need for a change in their roles and apply the same strategies and behavioral patterns as in traditional teaching. They lack understanding of the dynamic nature of active learning and may be over-dominant of the educational process. To efficiently implement the active learning approach, teachers need to know its underlying principles and develop an understanding of their new roles.

\section{Constructivist Background of Active Learning}

Active learning methods are widely-spread nowadays and often associate with constructivism. Although constructivism was not a pedagogical teaching, many of its followers developed practical applications of the theory in learning practice. Some scholars even believe that constructivist learning is a more appropriate name for active learning (Cooperstein and Kocevar-Weidinger 2004). Therefore, definition of teacher's roles in active learning should be essentially based on this philosophical framework.

The constructivist theory says that the concepts follow the action rather than precede it and that new experience builds on an already existing knowledge (Brainerd and Piaget 2003). The ideas of constructivists led to four important principles of active learning:

1. Learners construct their own meaning (learners are not passive knowledge absorbers, they make knowledge meaningful and useful in a new situation);

2. New learning builds on prior knowledge (learners combine old and new information and make sense of it);

3. Learning is enhanced by social interaction (learners resolve conflicting ideas in social settings participating in small group activities first and discussions within the entire class later);

4. Learning develops through "authentic" tasks (learners' activities should simulate those that will be encountered in real life) (Cooperstein and Kocevar-Weidinger 2004).

In this light, the new teacher's role can be better understood. Although instructors remain at the center of student learning, they should no longer act as a source of knowledge. Instead, their function is to create the environment where students will be engaged in learning in partnership with their teachers. Therefore, the correct interpretation of the new teacher's role at each instructional phase is crucial for successful learning.

\subsection{Bloom's Taxonomy of Cognitive Domains}

Present-day education is commonly outcome-based and one of the most widely used approaches to formulate the learning outcomes is built on the Taxonomy of Cognitive Domains by B.S. Bloom and his colleagues (Bloom, Englehart, Furst, Hill and Krathwohl 1956). The taxonomy was proposed in 1956 and consists of 6 cognitive levels, which are ordered as follows: Knowledge, Comprehension, Application, Analysis, Synthesis and Evaluation. Similar to the general constructivist theory, the major idea of the Bloom's taxonomy is that what educators want students to know can be arranged in a hierarchy from less to more complex (Huitt 2003). Thus, the levels in the taxonomy are successive, so that one level of cognitive skills should be mastered before the next level of cognitive skills can be reached. At this, the two lowest levels of the taxonomy - Knowledge and Comprehension - belong to the category of lower order thinking and represent a sound body of factual knowledge acting as the foundation of all thinking processes mastered at the four upper levels - Application, Analysis, Synthesis and Evaluation, - which, in their turn, belong to the category of higher order thinking (Kjos 1995) as shown in Figure 1.

\subsection{E Instructional Model}

Another perspective on constructivist learning that has become widely used nowadays was developed by the Biological Science Curriculum Study (BSCS) in 1987 and is known as the 5E Instructional Model (see Table 1). 


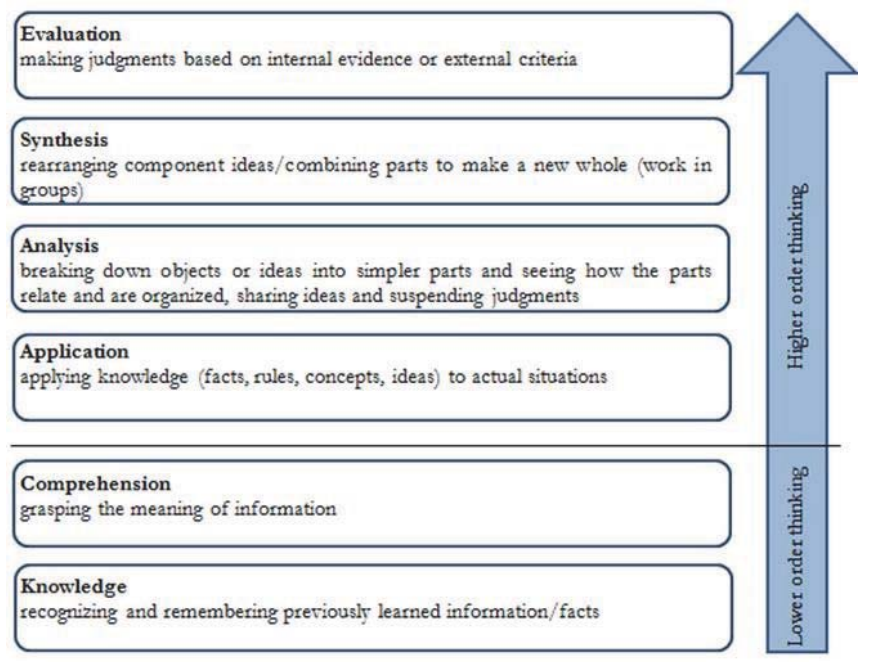

Figure 1. Bloom's taxonomy

The $5 \mathrm{E}$ Instructional Model is based on the idea that learning is not linear but successive and new knowledge connects to the existing knowledge to create a new concept. The structure and sequence of instruction is described in 5 phases of the model with the clear guidance on student's and instructor's behavior. Thus, the 5E Instructional Model can be used as another framework for defining the different teacher's roles that provide for successful attainment of educational objectives in active learning.

\section{Teacher's Roles in Active Learning}

\subsection{Methodology}

Both the Bloom's Taxonomy and the $5 \mathrm{E}$ Instructional Model share several common principles of describing the process of learning: 1) learning is successive, 2) learning requires first-hand knowledge, 3) learning extends in collaboration, and 4) learning creates new knowledge. Both models facilitate active learning and shift the educational paradigm from teachers to students. The extent of the Bloom's Taxonomy and the $5 \mathrm{E}$ Instructional Model have been previously considered for different purposes; however, little attention has been previously paid to their potential in defining the teacher's roles contributing to achieving learning objectives and outcomes.

Table 1. 5 E Instructional Model ${ }^{1}$

\begin{tabular}{l|l}
\hline Phase & Description \\
\hline Engage & $\begin{array}{l}\text { The teacher or a curriculum task accesses the learners' prior knowledge and helps them become engaged } \\
\text { in a new concept through the use of short activities that promote curiosity and elicit prior knowledge. The } \\
\text { activity should make connections between past and present learning experiences, expose prior } \\
\text { conceptions, and organize students' thinking toward the learning outcomes of current activities. }\end{array}$ \\
\hline Explore & $\begin{array}{l}\text { Exploration experiences provide students with a common base of activities within which current concepts } \\
\text { (i.e., misconceptions), processes, and skills are identified and conceptual change is facilitated. Learners } \\
\text { may complete lab activities that help them use prior knowledge to generate new ideas, explore questions } \\
\text { and possibilities, and design and conduct a preliminary investigation. }\end{array}$ \\
\hline Explain & $\begin{array}{l}\text { The explanation phase focuses students' attention on a particular aspect of their engagement and } \\
\text { exploration experiences and provides opportunities to demonstrate their conceptual understanding, process } \\
\text { skills, or behaviours. This phase also provides opportunities for teachers to directly introduce a concept, } \\
\text { process, or skill. Learners explain their understanding of the concept. An explanation from the teacher or the } \\
\text { curriculum may guide them toward a deeper understanding, which is a critical part of this phase. }\end{array}$ \\
\hline
\end{tabular}

1 See Bybee, Taylor, Gardner, Van Scotter, Powell, Westbrook and Landes 2006. 


\begin{tabular}{l|l}
\hline Extend/Elaborate & $\begin{array}{l}\text { Teachers challenge and extend students' conceptual understanding and skills. Through new experiences, } \\
\text { the students develop deeper and broader understanding, more information, and adequate skills. Students } \\
\text { apply their understanding of the concept by conducting additional activities. }\end{array}$ \\
\hline Evaluate & $\begin{array}{l}\text { The evaluation phase encourages students to assess their understanding and abilities and provides } \\
\text { opportunities for teachers to evaluate student progress toward achieving the educational objectives. }\end{array}$ \\
\hline
\end{tabular}

Apparently, teachers are very significant members of the educational process; however, their new vision lies in organization of the environment that provides for active learning. Modern teachers are no longer considered transmitters of knowledge but rather multi-role educators whose primary task is to correctly identify their role and behavioral mode according to objectives of each learning phase.

\subsection{Teaching Model}

On the basis of the established conformity of the described constructivist models seven teacher's roles have been defined and uniformly formulated to provide guidance for instructors and ensure the optimal extend of mastering the educational material at each cognitive level (Bloom's Taxonomy) and achieving the learning objectives (5 E Instructional Model):

- Motivator - motivates students for learning;

- Authority - provides students with ready-made concepts;

- Controller - controls that students make progress;

- Trainer - trains students to practically apply the previously acquired knowledge and skills;

- Moderator - moderates students' learning;

- Facilitator - facilitates the use of previously acquired knowledge and skills in new situations;

- Leader - stimulates students to reflect on their progress.

Figure 2 illustrates correspondence of the defined teacher's roles with the Bloom's cognitive levels and the 5E instructional phases in a single teaching model. Thus, in the Engage phase the teacher acts as a motivator and engages students by inspiring their interest and curiosity about the topic by means of considering interesting facts in the scope of the theme and elicits their prior knowledge by recalling their personal experience. The goal of this phase is to engage students and recognize previously learned information.

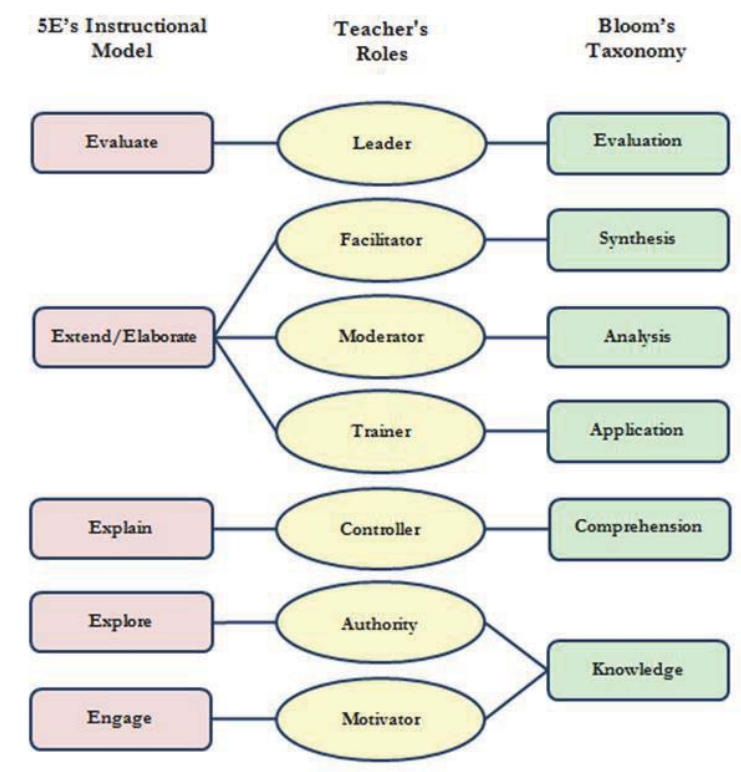

Figure 2. Teaching model in active learning 
The teacher's role at the Explore phase is that of an authority. In this role the teacher initiates exploration of new material by students, demonstrates new concepts, provides instructions and ready-made answers by means of listening, watching video and reading texts. The educational activities at this stage (multiple choice quizzes, (multiple) matching, labeling, naming and identifying; giving definitions (using the prompts); listing items) are aimed at exhibiting students' memory of learned materials, i.e. achieving the level of Knowledge in the Bloom's taxonomy.

At the Explain stage students are able to verbalize the conceptual understanding and the teacher encourages them to give clarifications and explanations in their own words and participate in discussions, i.e. controls that students make progress (acts as a controller). The students' behavior demonstrates that the students have reached the level of Comprehension in the Bloom's taxonomy.

In the proposed teaching model the Elaborate stage corresponds to 3 first levels of higher order thinking of the Bloom's taxonomy - Application, Analysis and Synthesis. Here the teacher plays 3 different roles: a trainer, a moderator and a facilitator. As a trainer the teacher offers students the tasks and assignment where they can use previously learned concepts in new situations, thus encourages them to extend their knowledge and skills in an active manner. Through this students learn at the level of Application in the Bloom's taxonomy.

As a moderator the teacher moderates students' activity by creating the necessary conditions for them to analyze, reflect and reconceive the current knowledge in a cooperative manner: the teacher organizes and observes students' interaction in groups where they conduct joint activities, predict, and form hypotheses or collect evidence to support generalizations, share ideas and suspend judgment, record observations, discuss tentative alternatives, i.e. act at the fourth level of understanding - Analysis.

The role of a facilitator contributes to achieving the next level of the Bloom's taxonomy - Synthesis - and implies simulating professional situations/problems, encouraging students to synthesize/create alternative solutions. Here students create a new personal knowledge from the elements that they have analyzed in the previous stage.

The final Evaluate stage corresponds to the highest level of the Bloom's taxonomy - Evaluation. This is a separate phase where students evaluate their own progress, present judgments against some set criteria and provide justified explanations to phenomena. The teacher's task of being a leader is to observe students' behaviors and skills and encourage them to assess their own learning.

\section{Results and Discussion}

The teaching model was developed to assist teachers in identifying appropriate teacher's roles at different stages of the educational process and is applicable to programs, individual modules or even specific topic built on the basis of active learning approaches. The defined teacher's roles were examined in a survey that was conducted among teachers of English at Tomsk Polytechnic University to study the role of the teacher in active learning. A statistical analysis of the survey was used to specify the best method for teaching students in every learning stage.

Twenty teachers were asked to answer the survey questions aimed at finding out:

- if they apply active learning methods;

- if they recognize various learning and instructional phases in the educational process;

- how teacher's behavioral mode changes at each instructional phase;

- which teacher's role enhances active learning to the greatest extent.

The respondents were offered the unified formulations of the defined teacher's roles (motivator, authority, controller, trainer, moderator, facilitator and evaluator) that were given in a randomized order.

The results show that all the teachers (100\%) use active learning methods and recognize various learning and instructional phases in the educational process (100\%). Some of them are also acquainted with the $5 \mathrm{E}$ Instructional Model to a various degree and even apply it for modeling their courses (30\%). However, only $40 \%$ of the participants believed that different instructional phases required different teacher's behavioral modes. The majority (60\%) confined to one or two roles, which, in their opinion, were sufficient to ensure successful students' learning. The most popular roles in the opinion of the teachers were that of a motivator and a moderator (see Figure 3).

It should be noted that the question on the teacher's role that enhances active learning to the greatest extent appeared troublesome for the respondents. As a result, $20 \%$ were at a loss to answer and other responses distributed among the roles of a leader, a motivator, a trainer and a facilitator (see Figure 4).

Figures 3 and 4 below show some quantitative results of the survey. 

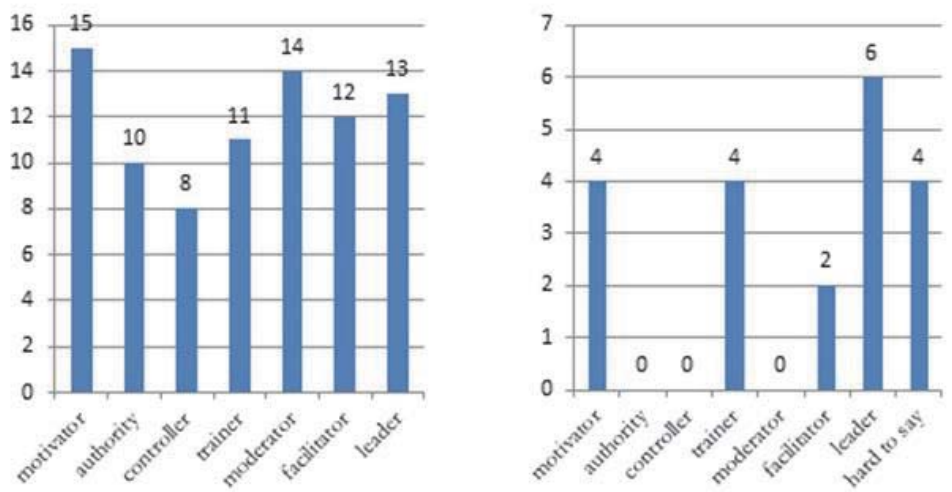

Figure 3. Teacher's roles in active learning. Figure 4. Teacher's role that enhances active learning to the greatest extent

The obtained results indicate that the teachers do not entirely realize that the change of learning and instructional phases implies a corresponding change of a teacher's role. As a consequence, teachers' adherence to one or two roles in the course of teaching leads to the situation when students remain on the low order thinking levels. This is exactly what the proposed model aims to eliminate by facilitating efficient planning and implementation of the learning process. The use of the teaching model may prevent from improper selection of a teaching strategy and contribute towards successful interactions between teachers and students in each learning phase.

\section{Conclusion}

The present paper has explained the recent need to shift from teaching to learning and considered the new role of a teacher in the modern educational environment, which is student centered and promotes active learning. It has further stated that modern instructors have to change their vision of a teacher's role from being transmitters of knowledge to becoming multi-role educators who are able to involve students in the process of gaining knowledge and independent development of skills. The major task of a modern teacher is to create an educational environment where students can obtain first-hand knowledge with appropriate teacher's support and guidance at each cognitive level.

The research has been soundly based on the Bloom's taxonomy and the 5E's Instructional model, which are commonly applied in active learning. These constructivists' teachings have been reviewed and compared to propose a teaching model aimed at providing educators with the guidelines on how to contribute to students' progress towards the desired knowledge and skills in different instructional phases.

The teaching model is not the only possible way to approach teaching that supports active learning. The model will also be refined and elaborated by means of experiments. However, in its present state it is already a helpful tool that can be used to improve the quality of learning.

\section{References}

Bloom, B., Englehart, M., Furst, E., Hill, W., \& Krathwohl, D. (1956). Taxonomy of educational objectives: The classification of educational goals. Handbook I: Cognitive domain. Handbook I: Cognitive domain. NY, Toronto: Longmans, Green.

Bonwell, C. C., \& Eison, J. A. (1991). Active learning: Creating excitement in the classroom. ASHE-Eric Higher Education Report No. 1. Washington, DC: George Washington University.

Brainerd, C. J., \& Piaget, J. (2003). Learning, research, and American education. In B. J. Zimmerman \& D. H. Schunk (Eds.), Educational psychology: A century of contributions (pp. 251-287). Mahwah, NJ, US: Lawrence Erlbaum Associates Publishers.

Bybee, R.W., Taylor, J.A., Gardner, A., Van Scotter, P., Powell, J.C., Westbrook, A., \& Landes, N. (2006). The BSCS 5E Instructional Model: Origins, Effectiveness and Applications. [Online] Available: http://www.bscs.org/sites/default/files/_legacy/BSCS_5E_ Instructional_Model-Executive_Summary_0.pdf_July 8, 2015)

Chickering, A. W., \& Gamson, Z. F. (1987). Seven principles for good practice in undergraduate education. AAHE Bulletin, 39(7), 3-7.

Chodasováa, Z., Tekulová, Z. (2015). Education of students and graduates of technical schools for contemporary requirements of practice. Procedia - Social and Behavioral Sciences, 174, 3170-3177.

Clapper, T. C. (2009). Moving away from teaching and becoming a facilitator of learning. PAILAL, 2 (2).

Cooperstein, S.E., \& Kocevar-Weidinger, E. (2004). Beyond active learning: a constructivist approach. Reference Services Review, 32, 
141-148.

Ercan, O. 2004. Active learning as a learning process. Education In the Light of Science and Mind, 54-55.

Gelisli, Y. (2009). The effect of student centered instructional approaches on student success. Procedia - Social and Behavioral Sciences, 1, 469-473.

Hargreaves, A. (2003) Teaching in the knowledge society: Education in the age of insecurity. NY: Teachers College Press.

Huitt, W., \& Hummel, J. (2003). Piaget's theory of cognitive development. Educational Psychology Interactive. Valdosta, GA: Valdosta State University

Jaques, D. (1992). Learning in groups (2nd ed.). Houston: Gulf Publishing Company.

Kjos, B. (1995). Brave New Schools. Harvest House Publishers.

Marton, F., \& Saljo, R. (1976). On qualitative differences in learning: I-outcomes and process. British Journal of Educational Psychology, 46 (1), 4-11.

McCarthy, J.P., \& Anderson, L. (2000). Active learning techniques versus traditional teaching styles: two experiments from history and political science. Innovative Higher Education, 24(4), 279-294.

McKeachie, W. J. (1999). Teaching tips: Strategies, research, and theory for college and university teachers. Boston: Houghton Mifflin.

Nolan, D. (2010). The Case for Active Learning Classrooms. [Online] Available: http://vcue.berkeley.edu/ActiveLearningClassrooms_ FinalReport.pdf_ (July 10, 2015)

Selevich, T., Selevich, O., Golubeva, T. (2015). The problems of assessing the competitiveness of Russian graduates. Procedia - Social and Behavioral Sciences, 174, 3611-3618.

Stiggins, R. J., \& Chappuis, J. (2011). An introduction to student-involved assessment for learning (6th ed.). Boston, MA: AddisonWesley.

Sutherland, T., \& Bonwell C. (1996). The active learning continuum: Choosing activities to engage students in the classroom. In T. Sutherland and C. Bonwell (eds.), Using active learning in college classes: A range of options for faculty, New Directions for Teaching and Learning (pp. 3-17). San Francisco: Jossey-Bass. 